International Journal of Agriculture, Environment and Bioresearch

Vol. 5, No. 03; 2020

ISSN: $2456-8643$

\title{
STUDY OF THE BIO-ACCUMULATION OF PESTICIDES IN APISMELLIFERA IN SOUSSMASSA REGION (SOUTHERN MOROCCO)
}

\author{
Aboudlou L. ${ }^{1}$, Hikamat A. ${ }^{1}$, Bari S. ${ }^{1}$, Abbassi M.1, ${ }^{2}$, Kaaya A. ${ }^{1}$ and Ait Ichou I. ${ }^{3}$ \\ ${ }^{1}$ Bioenvironment, Health And Bioresources Team, Faculty Of Sciences, University Ibn Zohr, Agadir, Morocco \\ ${ }^{2}$ Suprior Institute Of Maritime Fishing, Agadir, Morocco \\ ${ }^{3}$ Laboratory Lacape, Department Of Chemistry, Faculty Of Sciences, Ibn Zohr University, Agadir, Morocco
}

https://doi.org/10.35410/IJAEB.2020.5516

\begin{abstract}
The aim of this study is to assess the bioaccumulation of pesticides in the bee Apismellifera living by farming methods in the Souss Massa Region, known as an excellent agricultural area in South of Morocco. The study was conducted on bees collected from five sites in the region (Agadir and Ida Ougnid if considered as a control sites and Sebt El Guerdane, Houara and Taroudant, which are agricultural sites, suspected to be contaminated by pesticides).

Our preliminary results show the presence of pesticides: Neonicotinoids (Acetamiprid and Imidacloprid) and Organophosphorus (ChlorpyrifosEthyl) in samples of bees collected in the Sebt El Guerdane, Houara and Taroudant sites: These results lead to the supposition that behind the appearance of mortality rates, the behavioral and physiological disorders observed in bees in these sites can be probably due to the intoxication by the use of pesticides
\end{abstract}

Keywords: Apismellifera, Beekeeping, Bioaccumulation, Pesticides, Souss Massa Region.

\section{INTRODUCTION}

The Souss Massa is an agricultural region in the south of Morocco in which the use of pesticides is a routine practice. However, this orientation is not without consequences for the environment and human health. Indeed, several useful animal and plant species that are not targets of pesticides are often impacted by these products. In this context, beekeeping is one of the most affected sectors and often experiences mortalities, weakening and collapse of bees which are partly linked to pesticides. Beekeepers incriminate bee pathologies, in particular Varroa, bee intoxication by insecticide treatments and to the degradation of the floral cover of the environment. Faced to this situation, it is necessary to assess the risks associated to pesticides in order to contribute to set up a strategy for monitoring, preventing and protecting the state of health of human, environment and beekeeping resources.

The bee plays a key role in the production of citrus fruits. Orange blossoms produce abundant nectar (some flowers contain an average of $20 \mu \mathrm{l}$ ) (Pouvreau, 1984; Crane \& Walker, 1984). The flowering is very abundant, there are more than 60,000 flowers on an orange tree. The honey bee 
is the most abundant pollinating insect. Bees collect either nectar, pollen, or both. Each visit on a flower lasts 15 to $20 \mathrm{sec}$ for the nectar foragers and 5 to $8 \mathrm{~s}$ for the 34 pollen foragers.

Pesticides are a source of mortality in the bee, this essential insect for maintaining biodiversity. The bee participates in almost $80 \%$ in pollination, which makes it a key element in the survival of the plant world. For example, in France, the bee mortality rate increased from 5\% in the 1990 s, to $30 \%$ in 2017 , when neonicotinoids were introduced to the market.

Pesticides are used preventively and massively; they have a very high toxicity for invertebrates and a high toxicity for vertebrates; they persist in the environment for a very long time. For these reasons, they are a major cause of the loss of pollinators and they compromise the stability of the ecosystem. They are also a threat to food security.

In this context, the objective of our work is to study the effect of using pesticides on the serious disturbances and collapses observed in beekeepers hives and put forward the responsibility for pesticides used in the treatment of orchards around.

\section{MATERIALS AND METHODS}

\section{Sampling sites (Figure 1)}

The study covered five sites with three beekeepers per site. The choice of sites was based on their nature :

- Idaougnidif: which is a site characterized by an area (fixed limit of the foraging area), typical vegetation, limited road traffic and agricultural activity and no industrial activity.

- Agadir: which is an urban site characterized by a majority of urbanized area, small flora, significant automobile traffic, industrialization and absent or limited agricultural activity.

- Houara, SebtEl Guerdane and Taroudant: these sites are characterized by large areas of large field crops (dominated by orange trees) with beehives close to citrus orchards. 


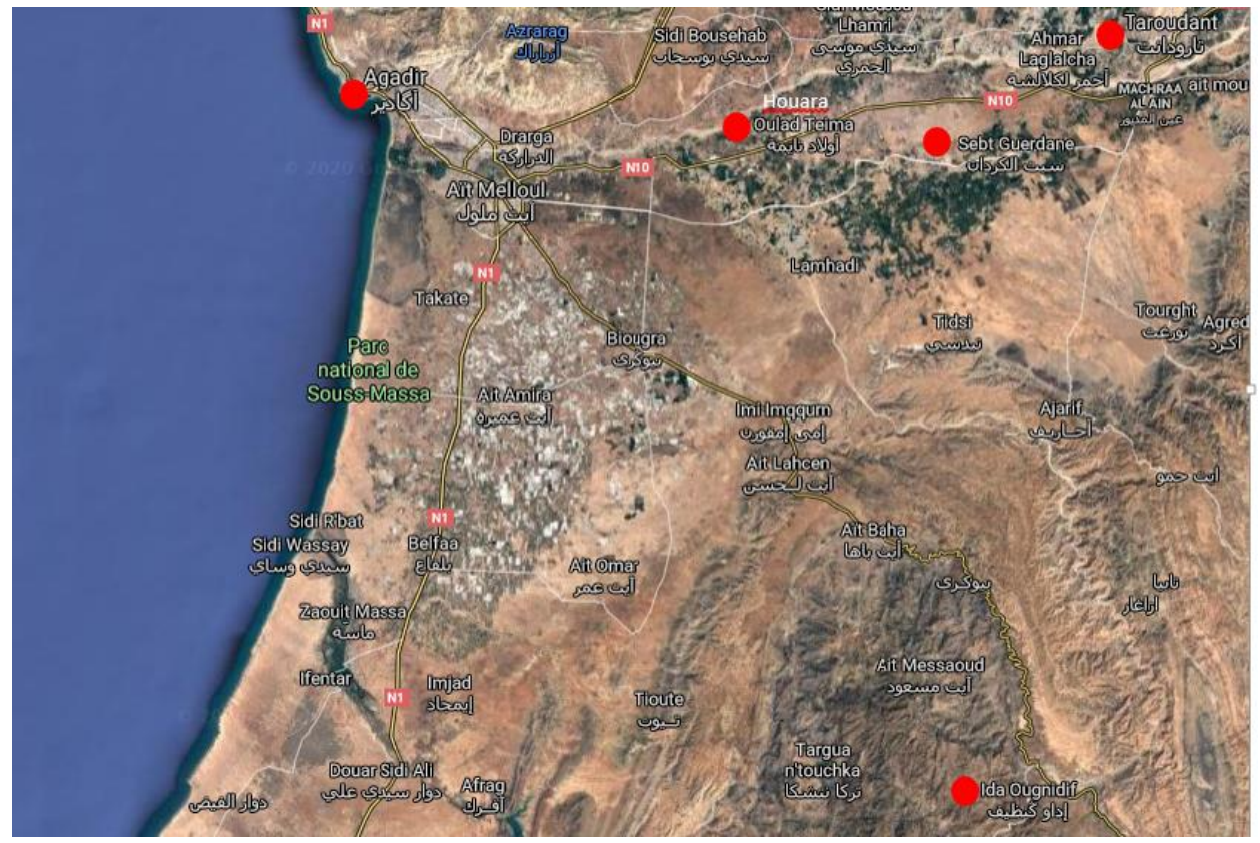

Figure 1: Sampling sites: Idaougnidif, Agadir, Houara, Sebt El Guerdane and Taroudant

\section{Beekeeping matrix collected}

The sampling plan was established in order to obtain the most faithful image possible of the contaminants brought back to the hive by the bee and to apprehend their possible transfers within the hive itself. Adult beesApismelliferawere collected directly by shaking a frame over a clean and dry aerate box and transported to our laboratory.

\section{Sample preparation}

Pesticides were extracted using the QuEChERS method (Quick, Easy, Cheap, Effective, Rugged and Safe). It is a technique for extracting pesticides and has the advantage of being quick, easy, inexpensive, effective, robust and reliable. This method was developed for the first time by Anastassiadeset al. (2003) for the analysis of pesticide residues. It is based on the principle of liquid-liquid extraction with an organic solvent in the presence of QuEChERS salts and buffers followed by purification.

The identification is done by the presence of the two transitions ( 2 MRM for the MS / MS system) using the liquid chromatography coupled with mass spectrometry (LC MS / MS).

\section{RESULTS AND DISCUSSION}

Apismellifera collected in sites of Agadir and Ida Ougnidif, previously considered as a controlsites,show no contamination by pesticides but in the sites of Houara,SebtEl Guerdane and Taroudant pesticides were detected: two neonicotinoids (Acetamiprid and Imidacloprid) and an organophosphorus (ChlorpyrifosEthyl). The analysis results of samples collected during this study using LCMS / MS are given in the table1: 
Vol. 5, No. 03; 2020

ISSN: $2456-8643$

Table 1: Results of variance pesticides LCMS / MS analysis of Apismellifera collected in sites of Houara,SebtEl Guerdane and Taroudant(B :Beekeeper ; LOD : Limit of Detection ; LOQ :Limit of Quantification).

\begin{tabular}{|c|c|c|c|c|c|c|c|c|c|c|c|c|}
\hline & \multirow{2}{*}{$\begin{array}{l}\text { LO } \\
\text { D }\end{array}$} & \multirow{2}{*}{$\begin{array}{l}\text { LO } \\
\text { Q }\end{array}$} & \multirow{2}{*}{$\begin{array}{l}\text { Mont } \\
\text { h2017 }\end{array}$} & \multicolumn{3}{|c|}{ Taroudant } & \multicolumn{3}{|c|}{ SebtEl Guerdane } & \multicolumn{3}{|c|}{ Houara } \\
\hline & & & & B1 & B2 & B3 & B1 & B2 & B3 & $\overline{\text { B1 }}$ & B2 & $\overline{B 3}$ \\
\hline \multirow{4}{*}{$\begin{array}{l}\text { Acétamipride } \\
(\mu \mathrm{g} / \mathrm{Kg})\end{array}$} & \multirow[t]{4}{*}{0,3} & \multirow[t]{4}{*}{1} & April & 0,5 & 0,4 & 0,4 & 0,6 & 0,3 & 0,3 & 0,5 & 0,3 & 0,3 \\
\hline & & & May & 0,4 & 0,2 & 0,2 & 0,6 & 0,2 & 0,3 & 0,5 & 0,2 & 0,3 \\
\hline & & & June & 0,3 & 0,1 & 0,1 & 0,3 & $<\mathrm{LQ}$ & 0,1 & 0,3 & 0.2 & 0,2 \\
\hline & & & July & 0,3 & $<\mathrm{LQ}$ & $<\mathrm{LQ}$ & 0,3 & $<\mathrm{LQ}$ & $\angle \mathrm{LQ}$ & 0,3 & $<\mathrm{LQ}$ & 0.1 \\
\hline \multirow{4}{*}{$\begin{array}{l}\text { Imidaclopride } \\
(\mu \mathrm{g} / \mathrm{Kg})\end{array}$} & \multirow[t]{4}{*}{0,3} & \multirow[t]{4}{*}{1} & April & 0.8 & 0.7 & 0.6 & 0.9 & 0.7 & 0.6 & 0.8 & 0.6 & 0.4 \\
\hline & & & May & 0,7 & 0,6 & 0,5 & 0,9 & 0,7 & 0,5 & 0,8 & 0,6 & 0,3 \\
\hline & & & June & 0,5 & 0,4 & 0,3 & 0,3 & 0,2 & 0,3 & 0,5 & $<\mathrm{LQ}$ & $<L Q$ \\
\hline & & & July & $\begin{array}{l}<\mathrm{L} \\
\mathrm{Q}\end{array}$ & $<L Q$ & $<\mathrm{LQ}$ & $\begin{array}{l}<\mathrm{L} \\
\mathrm{Q}\end{array}$ & $<\mathrm{LQ}$ & $<\mathrm{LQ}$ & $\begin{array}{l}<\mathrm{L} \\
\mathrm{Q}\end{array}$ & $<L Q$ & $<\mathrm{LQ}$ \\
\hline \multirow{4}{*}{$\begin{array}{l}\text { ChlorpyrifosEth } \\
\text { yl } \\
(\mu \mathrm{g} / \mathrm{Kg})\end{array}$} & \multirow[t]{4}{*}{0,3} & \multirow[t]{4}{*}{1,2} & April & 2.5 & 2.5 & 2.5 & 2.8 & 2.4 & 2.5 & 2.0 & 2.2 & 2.3 \\
\hline & & & May & 2,7 & 2,2 & 2,4 & 2,6 & 2,1 & 2,5 & 2,0 & 2,0 & 2,1 \\
\hline & & & June & 1,0 & 2,0 & 2,1 & 1,2 & 1 & 2 & 1,8 & 1,9 & 2,1 \\
\hline & & & July & 1,0 & $<\mathrm{LQ}$ & $<\mathrm{LQ}$ & 0,9 & $<\mathrm{LQ}$ & $<L Q$ & 1,0 & $<\mathrm{LQ}$ & $<\mathrm{LQ}$ \\
\hline
\end{tabular}

The assay results revealed the detection of pesticides only in samples from Houara, SebtEl Guerdane and Taroudant with recording of different and decreasing values from April to July 2017 (Figures 2, 3 and 4).

The simultaneous absence of pesticide residues in bees from Agadir and Ida Ougnidif and their strong presence in other beekeepers appeared to be significantly correlated with the high use of pesticides in citrus orchards in these sites. 
International Journal of Agriculture, Environment and Bioresearch

Vol. 5, No. 03; 2020

ISSN: $2456-8643$

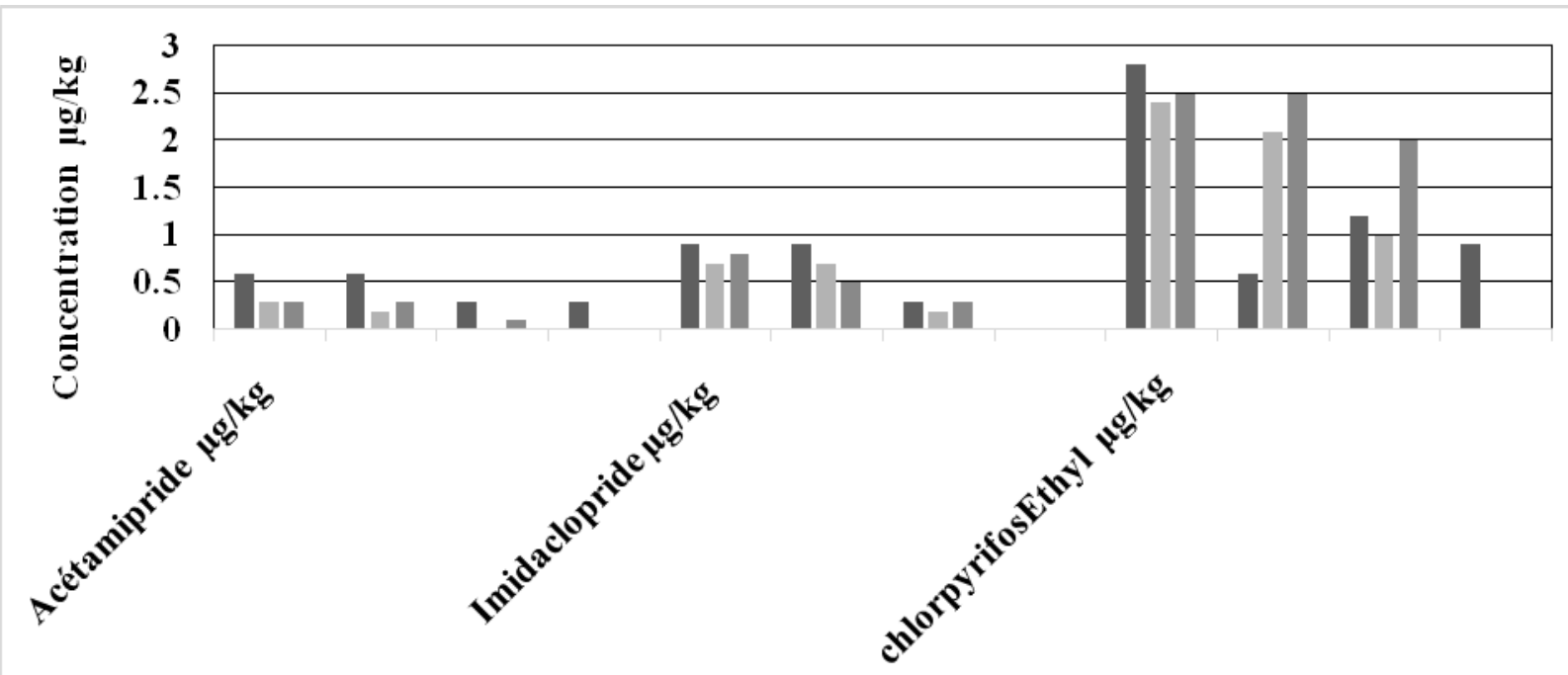

Months:April,May,June,July

- Beekeeper 1 Beekeeper 2 Beekeeper 3

Figure 2:Variation in concentrations of detected pesticides during the study months in Apismellifera collected SebtEl Guerdane

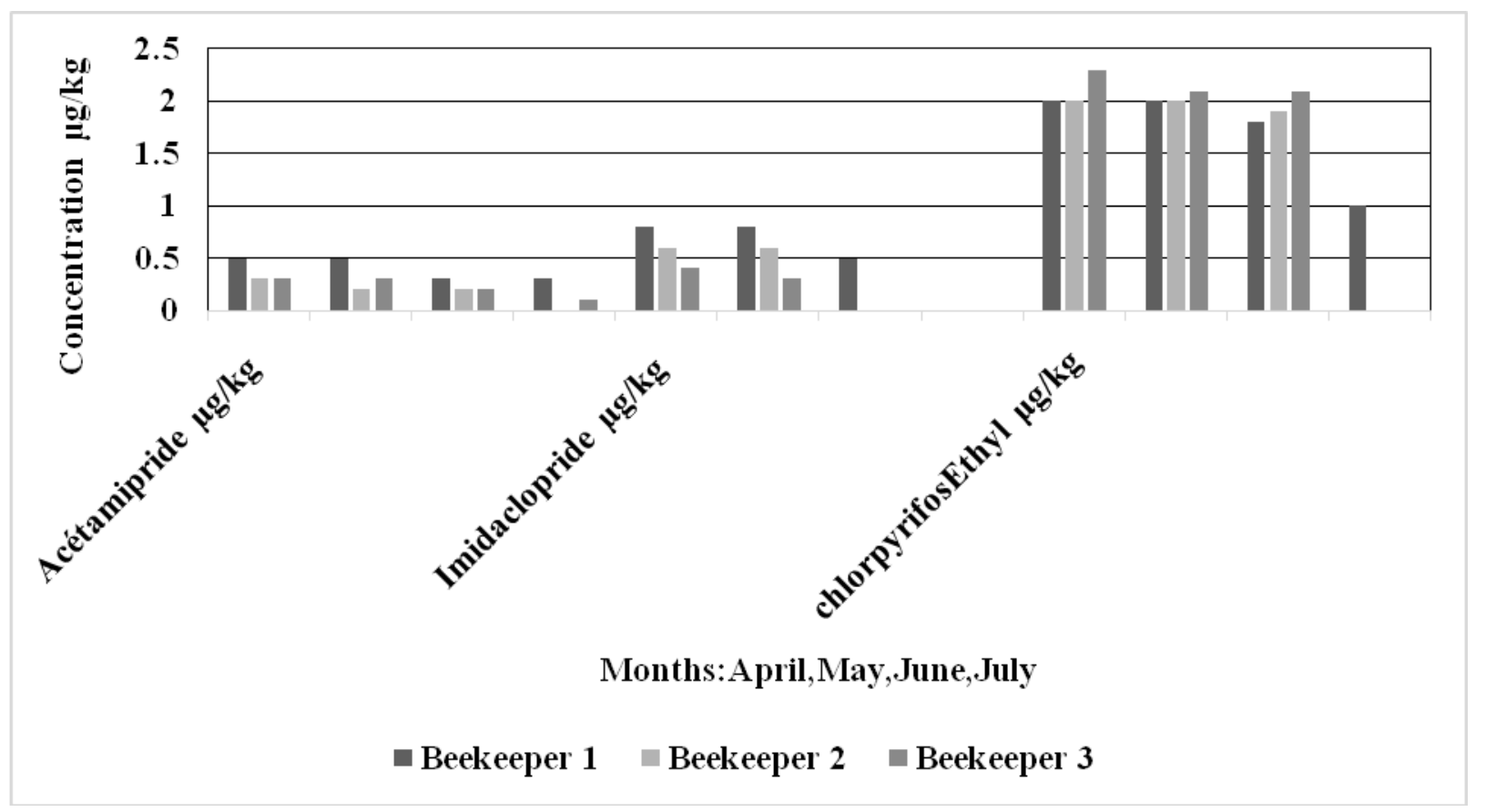

Figure 3: Variation in concentrations of detected pesticides during the study months in Apismellifera collected in Houara 


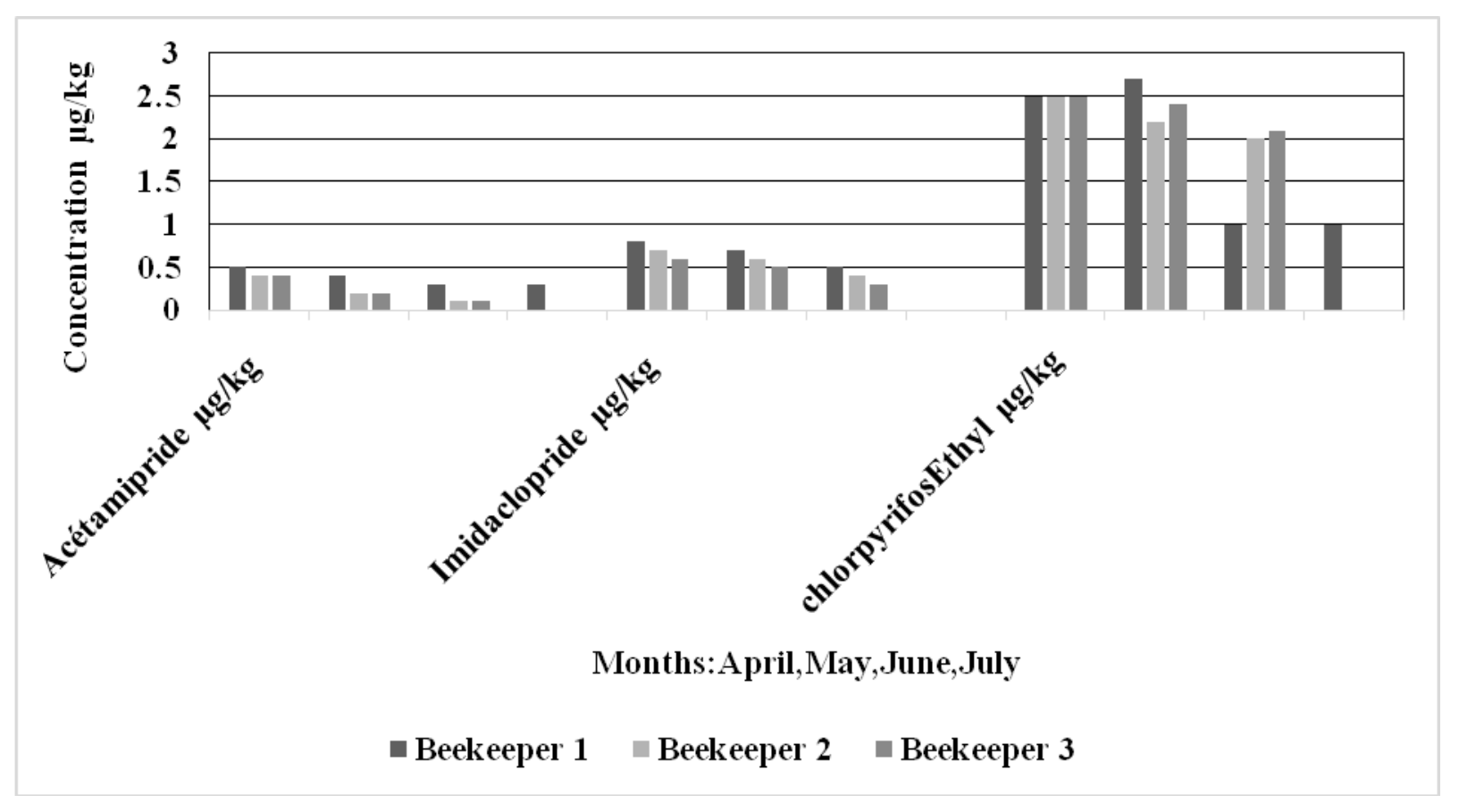

Figure 4: Variation in concentrations of detected pesticides during the study months in in Apismellifera collected Taroudant

The trend towards a decrease in the concentrations of the three active substances found in the three sites pushed research towards the treatments used in citrus fruits just beside. Indeed, it was found that it the contamination is linked to the use of these treatments along the agricultural season which generallystarts from the month of March and ends at the end of June. Such observations could explain the decontamination of the hives at the end of the sampling period and the decrease in the fall hives among beekeepers observed in the region.

Another relevant observation is the high concentration of chlorpyrifosEthyl observed compared to the other pesticides detected and measured during all the months of the study as shown in Figures 2, 3 and 4 . This difference can be explained by the increase in frequency of the use of chlorpyrifosEthyl per day, and consequently the contamination of bees by significant quantities of this pesticide by volatilization or during their presence in agricultural crops.

Given this situation and according to the results of our study which revealed the presence of pesticides in sites close to these crops, we can explain the bee disorders observed by the contamination by pesticides detected in the samples, namely the neonicotinoids represented here by Acetamiprid, Imidacloprid, and the organophosphates represented by ChlorpyrifosEthyl.

The result is, within minutes, or even seconds, vision and other sense disturbances, loss of motor control (general paralysis), possibly followed by paralysis of the heart muscle and breathing muscles, leading upon death (Pelletier, 2010). 
Vol. 5, No. 03; 2020

ISSN: $2456-8643$

Studies interested in the effects of imidacloprid have shown that this pesticide and these metabolites are highly toxic to bees.

Imidacloprid is considered to be one of the pesticides that cause toxicity at low doses. In antennal lobe neurons, the characterization of type I currents of nAChR, which has slow desensitization, and type II currents, which exhibit rapid desensitization, strongly suggest the presence of at least two different types of nAChRs. The presence of two types of receptors displaying different affinities for imidacloprid and its metabolites has been proposed on the basis of the complex toxicity profile after chronic exposures in bees; The presence of two types of imidacloprid targets, which could explain the differential toxicity of imidacloprid at low and very low doses observed in bees (Simon-Delsoet al. 2014).

Imidacloprid also affects the metabolism, reproduction and development of the colony, and the mobility of the bee. It has been shown that doses of $2 \mu \mathrm{g} / \mathrm{L}$ have an impact on the energy metabolism of larvae and workers by affecting detoxification, the intermediate and energy metabolic pathways, and by this action imidacloprid alters brain metabolism in bees. which leads to an increase in cytochrome oxidase in the peduncle bodies (Pisa et al. 2014).

These negative effects of imidacloprid on motor activity depend on the dose of insecticides, the lowest dose $125 \mathrm{ng}$ per bee resulted in increased motor activity, while the highest dose 25 to 20 ng per bees induce a decrease in this activity (Desneuxet al. 2007).Colin et al. (2019) revealed that imidaclopride influences worker foraging during the larval stage strongly.

The second neonicotinoid highlighted by our study is acetamiprid. T the harmful effects of this pesticide are tested. The results obtained with acetamiprid have shown that the action of neonicotinoids depends on the level of 1 exposure and cannot be generalized to neighboring destructured compounds. Unlike contact exposure and oral exposure to acetamiprid, which has affected the long-term preservation of olfactory learning (Pisa et al. 2014).

Badawyet al. (2014) demonstrated that acetamiprid at LD50 $=1.60 \mu \mathrm{g} /$ bee causes bee mortality after exposure for 24 hours.

Field and laboratory studies that try to test lethal doses under field conditions have demonstrated that chronic oral or contact exposure for 10 to 11 days to $1 \mu \mathrm{g} /$ acetamiprid bee can lead to worker mortality (Pisa et al. 2014) other results reveal that a dose of $0.25 \mathrm{~g} / \mathrm{L}$ of acetamiprid causes 20\% mortality in A. mellifera bees 48 hours after treatment (Stanley et al. 2014).

Acetamiprid and its metabolites can also affect the memory process and the metabolism of acetamiprid apparently results in different metabolites in bees, among which 6-chloronicotinic acid is toxic by chronic exposure, but not by acute exposure and remains stable for at least $72 \mathrm{~h}$, especially in the head and thorax. Given the presence of multiple active metabolites over time, it is very difficult to verify which stages of the memory process (acquisition, consolidation or recovery) are affected by acetamiprid (Pisa et al. 2014). in addition to the use of synthetic insecticides can also cause changes in the social behavior of bees such as increased agitation, aggression and pollen contamination (Stanley et al. 2014). 
The toxicity of acetamiprid can also alter the activity of certain key enzymes in the bee's functional processes. Studies have reported that exposure to a dose of $0.6 \mathrm{mg} / \mathrm{L}$ of acetamiprid leads to a decrease in the specific activity of AChE by 0.50 and $0.30 \mathrm{nmol}$ hydrolysis of AChE / $\mathrm{mg}$ protein / $\mathrm{min}$ in the head and thorax respectively. It can be concluded that this pesticide has an inhibitory action on AChE in other enzymes, almost the same results have been found, carboxylesterases are the main enzymes for detoxification of pesticides.

Our previous comparative study of AChE activity of Apismeelliferaas biomarker of pesticides contamination conducted in Houara region (considered as a contaminated site) and Tassila (considered as a control site) showed a high AChE activity in animals from contaminated sites (Houara),compared to those recolted in the control site (Tassila) (Aboudlouet al. 2018).

The third pesticide detected by the analysis in our study is ChlorpyrifosEthyl, which belongs to the family of organophosphates, it controls the attack of Coleoptera, Diptera, Homoptera and Lepidoptera. It is sprayed on fruit trees (apple, citrus, hazelnut ...), strawberry, banana, potato, tobacco, rice, cotton, alfalfa, cereals, corn, ornamental plants and in forests, chlorpyriphosethyl is classified as toxic to bees (Rafalimanana, 2003).

Many results show that using doses of neonicotinoids may cause honeybee colony failure, not only because the exposed workers start foraging when younger, which unbalances the agebased division of labor (Jacob et al. 2019). Also because of faster biochemical senescence.Its also an important fact that may help explain controversial mechanisms of colony depopulation when it is exposed to sublethal neonicotinoid.

Chlorpyrifos (CPF) has been shown to be metabolically activated by oxidative desulfurization to give its metabolite chlorpyrifosoxon (CPF oxon) which can inhibit acetylcholinesterase (AChE) by phosphorylation of its serine sites (Rehman et al. 2012). Inhibition of AChE can induce a general disturbance in all systems because it is an important component in all synaptic transmissions (Nicolas Desneuxet al. 2007).

Numerous studies have also suggested that CPF could induce the production of ROS in bee nerve tissue, resulting in neurotoxic effects by a mechanism that involves the high toxicity of $\mathrm{OH}$ radical instead of inhibition of acetylcholinesterase. The neurotoxicity of CPF increases the formation of malondialdehyde in the bee, malondialdehyde is a reactive substance thiobarbituric acid (TBARS) and a lipid peroxidation marker for cell membrane damage, it is also the end product of oxidative stress in biological systems. After pathophysiology or xenobiotic toxicity, significant increases in malondialdehyde levels in the bee's nervous system by different levels of CPF exposures showed dose dependent slope, meaning that apparent oxidative stress was taking place by action of the pesticide. Other investigations have reported that the toxicity caused by CPF may be due to the induction of oxidative stress in the central nervous system of the bee (Rehman et al. 2012).

Another study shows that exposure to a $2 \mathrm{~g} / \mathrm{L}$ dose of chlorpyrifos causes $100 \%$ bee mortality 48 hours after treatment, and this can be explained by the high toxicity of chlorpyrifos to bees (Stanley et al. 2014). 
Vol. 5, No. 03; 2020

ISSN: $2456-8643$

\section{CONCLUSION}

Pesticides as a whole are known by their harmful effects on the organisms they affect, our study of the evaluation of the impact of these substances on the bee of the Souss Massa region confirmed this observation through results obtained which showed the presence of the pesticides implicated in the appearance of the disorders observed in bees during field observations.

The information available in the literature shows that these pesticides are classified among the most heavily used and the most toxic for bees. These pesticides can cause many different disorders depending on the dose of these substances in the bee, which can go up to when the organism dies, the toxic effects of these three pesticides can lead to mortality, physiological disorders (development, neurotoxic, fertility, immunity, etc.), and behavioral disorders (navigation and orientation, mobility, etc.).

\section{REFERENCES}

Aboudlaou L., B. Ouzyou, M. Agnaou, A. Hikmat, A. Laalaoui, A. Banaoui, I. AitICHou, A. Kaaya (2018). Use of acetylcholinesterase in Apismellifera as a biomarker of pesticides pollution in Souss Massa Region (South of Morocco). International Journal of Agriculture, Environment and Bioresearch, Vol. 3, No. 03; pp 370-382.

Badawy M. E. I., H. M. Nasr and E. I. Rabea (2014). Toxicity and biochemical changes in the honey bee Apis mellifera exposed to four insecticides under laboratory conditions. Apidologie 46: pp 177-193.

Balayiannis .G and P.Balayiannis, (2008). Bee honey as an environmental bionindicator of pesticides occurrence i six agricultural areas of greece.Arch Environ Contam Toxicol, 55 : pp 462-470.

Colin T., Meikle W.G., Wu X., Barron A.B. (2019) Traces of a neonicotinoid induce precocious foraging and reduce foraging performance in honey bees. Environ. Sci. Technol. 53 , 82528261

Crane E. (1984). Bees honey and pollen as indicators of metals in the environment. Bee World, 55: $p$ p 47-49

Decourtye A., Lecompte P., Pierre J., Chauzat M. P. and Thiebeau P. (2007). Introduction de jachères florales en zones de grandes cultures : comment mieux concilier agriculture,biodiversité et apiculture ? Courrier de l'Environnement de l'INRA : pp 33-56.

Desneux N., A. Decourtye and J. M. Delpuech (2007). The sublethal effects of pesticides on beneficial arthropods. Annual Review of Entomology, pp 52: 28

Jacob C.R.O., Malaquias J.B., Zanardi O.Z., Silva C.A.S., Jacob J.F.O. et al (2019) Oral acute toxicity and impact of neonicotinoids on Apis mellifera L. and Scaptotrigona postica Latreille (Hymenoptera: Apidae). Ecotoxicology 28 , 744-753

Michelangelo Anastassiades, Steven J Lehotay, DarinkaStajnbaher, Frank J Schenck (2003) Fast and easy multiresidue method employing acetonitrile extraction/partitioning and "dispersive solid-phase" AOAC. Int. 86: pp 412-431. 
Vol. 5, No. 03; 2020

ISSN: $2456-8643$

Pelletier N. (2010). Le déclin des populations d'abeilles au québec : causes probables, impacts et recommandations.Centre Universitaire de Formation en Environnement Université de Sherbrooke, 77 pages .

Perugini M, Manera M, Grotta L, Abete M. C., Tarasco R. and Amonera M. (2011). Heavy metal $(\mathrm{Hg}, \mathrm{Cr}, \mathrm{Cd}$ and $\mathrm{Pb})$ contamination in urban areas and wildlife reserves: Honeybees as bioindicators. Biol. Trace Elem. Res. 140: pp 170-176.

Pisa L. W., V. Amaral-Rogers, L. P. Belzunces, J. M. Bonmatin, C. A. Downs, D. Goulson, D. P.Kreutzweiser, C. Krupke, M. Liess, M. McField, C. A. Morrissey, D. A. Noome, J. Settele, N. SimonDelso, J.D.Stark, J.P.Van der Sluijs, H.Van Dyck and M.Wiemers (2014). Effets des néonicotinoïdes et du fipronil sur les invertébrés. Environ. Sci. Pollut., pp 20.

Pouvreau,A.(1984). Biologie et écologie des bourdons. In: Pollinisation et productions végétales, Edited byPesson,P.andLouveauxJ. pp 595-630.Paris, INRA.

Rafalimanana H.J. (2003). Evaluation des effets d'insecticides sur deux types d'Hyménoptères auxilliaires des cultures, l'abeille domestique (Apis mellifera L.) et des parasitoïdes de pucerons: études de terrain à Madagascar et de laboratoire en France.Thèse Doctorat, Institut National Agronomique Paris- Grignon,207 pages.

Rehman, S. and M. I. Waliullah (2012). Chlorpyrifos-induced neuro-oxidative damage in bee. Toxicology and Environmental Health Sciences, 4(1): pp 30-36.

Sabatini A. G. (2005). L'abeille bioindicateur, l'abeille sentinelle de l'environnement. SAGE Pesticides 20110, Vol 5, $N^{\circ} 108$, pp 12-16.

Simon-Delso., N., V. Amaral-Rogers., L. P. Belzunces., J. M. Bonmatin., M. Chagnon., C. Downs., L. Furlan., D. W. Gibbons., C. Giorio., V.Girolami., D. Goulson., D. P. Kreutzweiser., C. H. Krupke., M. Liess., E. Long., M. McField., P. Mineau., E. A. D. Mitchell., C. A. Morrissey., D. A. Noome., L. Pisa., J. Settele., J. D. Stark., A. Tapparo., H. V. Dyck., J. V. Praagh., J. P. V. Sluijs., P. R. Whitehorn; and M. Wiemer (2014 ). Pesticides néonicotinoïdes : Tendances, usages et modes d'action des métabolites. Environ Sci Pollut Res: $p p 12$.

Stanley, J., Khushboo Sah, S.K. Jain, J.C. Bhatt and S. N. Sushil (2014). Evaluation of pesticide toxicity at their field recommended doses to honeybees, Apis cerana and Apis mellifera through laboratory, semi-field and field studies.Chemosphere119: pp 668-674. 